\title{
Germany stumbles on enacting plan to integrate eastern scientists
}

Berlin. The fall of the Berlin Wall also destroyed the regime within which most scientists in East Germany had worked all their lives. All research institutes were closed down, university professors were sacked and a new, smaller research system was created out of the ashes. Now these scientists are being asked to bear another burden: nearly 2,000 who were promised university positions may now find themselves jobless because the universities do not want them.

Nearly all research in communist East Germany was carried out in the 57 institutes of the Academy of Sciences, with universities being given little chance to conduct serious research. A new law established in October 1990 after reunification - the Higher Education Renewal Programme was intended to mould East German research into a western system based on the unity of teaching and research.

But the transition has not been easy. Academy institutes, which in 1989 employed 24,000 people, were grossly overstaffed. Many employees were engineers who built scientific equipment that they were unable to buy from the West and who became superfluous when the two German economies were combined. By the end of 1991, when the institutes were closed, migration, early retirement and mobility allowances reduced this number to 15,000 - still far too many.

Germany's science council, the Wissenschftsrat, was called in to evaluate the work of the institutions and recommended that 6,700 staff be retained in newly created institutes (in fact 7,200 are now employed). It also suggested the integration by the end of 1992 of an additional 1,900 into eastern Germany's 10 universities and 400-odd institutes of higher education. But the plan has hit serious problems because the universities are unwilling to offer the scientists contracts.

The reintegration programme, known as WIP (Wissenschaftler-Integrationsprogramm), was originally given DM400 million (US\$250 million) for four years. Applicants were required to submit a research plan, and successful candidates (now known as WIPers) would be paid for a year of work at one of the new institutes. They would use this time to seek a university job, helped by a coordinating body, KAI, set up for this purpose. Once hired, the scientists would continue to be paid by the federal government, with regional government picking up an increasing share of the salary each year. After three years, the WIPers would be taken on as normal university staff.

But problems soon arose. Universities

forced to reduce staff numbers by half after the science council concluded that they were grossly oversubscribed did not appreciate being asked to take in outsiders at a further cost to their own numbers. At the same time, there was no place for the scientists to work because the universities had done virtually

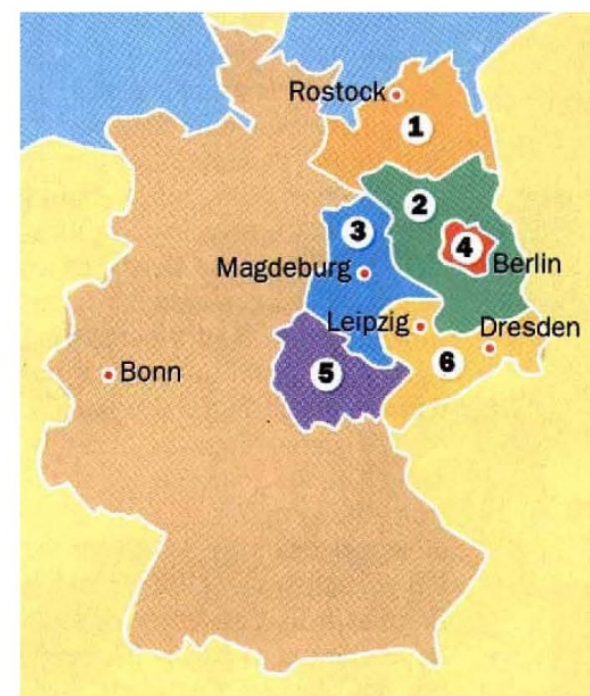

In addition to transferring researchers from research institutes to universities, the Higher Education Renewal Programme dictates a regional redistribution. Those in the WIP programme must be prepared to distribute themselves more evenly through the eastern Länder, and less than half will be able to stay in Berlin.

no research. Debate continues on who should pay the rent for laboratories to be set up if the WIPers are taken on.

The universities are also concerned that in three years they may be obliged to give any available permanent position to a WIPer instead of advertising it for open competition, thereby reducing their ability to attract the best talent. And they worry that they will be asked to make a contribution if the WIPers use up the DM600 million now allocated to the programme.

The programme also puts a strain on the Länder (regional governments). Although the exact amount of money allocated to the programme is known, the proportion to be paid by the Länder, which are normally financially responsible for universities, is still being negotiated. Two weeks ago, the federal and Länder governments agreed to a 75:25 split for 1994 and set individual salaries at 84 per cent of the rate for western Germany. But the terms of funding for the last two years of the programme remain uncertain.

WIPers themselves have found the process difficult. Accustomed to having a job for life, they had no experience of writing

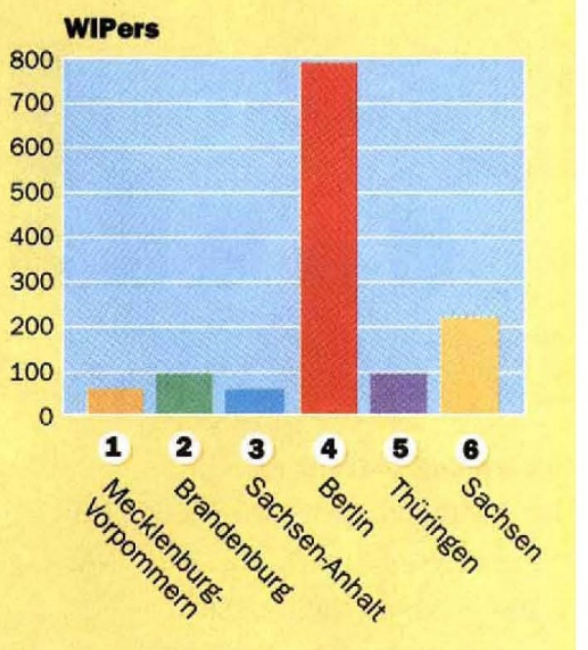

grant applications and working under the pressure of uncertain funding. So far, only 1,234 of 1,920 have entered into negotiations with universities for permanent positions and only 85 have been given contracts.

Some blame the WIPers for the problems. Last month, for example, the ministers

of the Länder stated that "some WIPers need to make much more effort to integrate into the universities". But Hartmut Schulz of KAI says that such criticism is unfair. There are many reasons why it has been difficult for researchers to form links with universities, he says, with some not even sure that particular departments would survive investigations into the competence and integrity of the professors.

All of these problems slowed negotiations to such an extent that the federal government was forced to double its initial oneyear period of support. But no more extensions are expected, and with most WIPers older than 40 , those who do not negotiate a contract during this time fear that they may never again work as scientists.

Despite the problems, there is considerable optimism that most WIPers will, by hook or by crook, have been given contracts by the end of the year. But the idea of true integration - that is, a normal university post - now seems little more than a pipedream. For many the WIP programme is likely to be a stressful prelude to permanent unemployment.

Alison Abbott 